\title{
Cyclo[4]carbazole, An Iodide Anion Macrocyclic Receptor
}

Huangtianzhi Zhu, ${ }^{\mathrm{a}}$ Bingbing Shi, ${ }^{\mathrm{a}}$ Kexian Chen, ${ }^{\mathrm{b}}$ Peifa Wei, ${ }^{\mathrm{a}}$ Danyu Xia, ${ }^{\mathrm{a}}$ Julfikar Hassan Mondal, ${ }^{\mathrm{a}}$ and Feihe Huang*a

${ }^{a}$ State Key Laboratory of Chemical Engineering, Center for Chemistry of High-Performance \& Novel Materials, Department of Chemistry, Zhejiang University, Hangzhou 310027, P. R. China; Fax and Tel: +86-571-8795-3189; Email: fhuang@zju.edu.cn

${ }^{b}$ College of Food and Biology Engineering, Zhejiang Gongshang University, Hangzhou, Zhejiang 310018, P. R. China

\section{Supporting Information}

1. Materials and methods

2. Synthesis of $\mathrm{Cy}[4] \mathrm{C}$

3. Fluorescence emission spectra of $\mathbf{C y}[4] \mathrm{C}$ in the presence and absence of iodide anion S7

4. Determination of the complexation kinetics for $\mathbf{C y}[4] \mathrm{C}$ and iodide anion S7

5. Partial ${ }^{1} H$ NMR spectra of $C y[4] C$ with various equivalents of TBAI

6. High-resolution mass spectrum of a mixture of $\boldsymbol{C y}[4] C$ and iodide anion $\quad$ S8

7. PM6 molecular model of the Cy[4]C/iodide anion complex S9

8. Determination of association constant $\left(K_{a}\right)$ of $\boldsymbol{C y}[\mathbf{4}] \boldsymbol{C}$ and iodide anion S9

9. X-ray crystal data for $\mathbf{C y}[4] C \quad S 10$

10. X-ray crystal data for the complex of $\mathbf{C y}[4] \boldsymbol{C}$ and chloroform $\quad$ S10

11. References S11 


\section{Materials and methods}

All reagents including 3,6-dibromocarbazole, $\mathrm{Ni}[\mathrm{COD}]_{2}$, and dry $N, N^{\prime}$-dimethylformamide (DMF) were commercially available and used directly. A Bruker Avance DMX 600 spectrophotometer or a Bruker Avance DMX 400 spectrophotometer was used to record ${ }^{1} \mathrm{H}$ or ${ }^{13} \mathrm{C}$ NMR spectra with deuterated solvent as the lock; the internal reference was TMS or residual solvent. UV-vis spectroscopy was performed on a Shimadzu UV-2550 instrument at room temperature. The crystal data were collected on an Oxford Diffraction Xcalibur Atlas Gemini ultra. High-resolution mass spectrometric experiments were performed with a Bruker 7-Tesla FT-ICR mass spectrometer equipped with an electrospray source (Billerica, MA, USA). The fluorescence experiments were conducted on a RF-5301 spectrofluorophotometer (Shimadzu Corporation, Japan). The melting points were collected on a SHPSIC WRS-2 automatic melting point apparatus. 


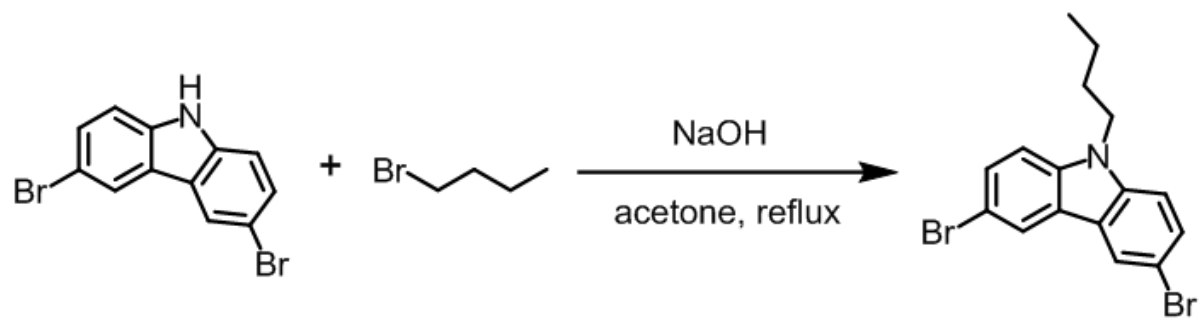

Under the protection of argon, 3,6-dibromocarbazole $(6.50 \mathrm{~g}, 20.0 \mathrm{mmol})$ was dissolved in $100 \mathrm{~mL}$ of acetone. Sodium hydroxide $(1.20 \mathrm{~g}, 30.0 \mathrm{mmol})$ was added carefully under vigorous stirring at $60{ }^{\circ} \mathrm{C}$ for $30 \mathrm{~min}$. To this solution, 1-bromobutane $(4.11 \mathrm{~g}, 30.0 \mathrm{mmol})$ was added dropwise. After that, the mixture was stirred at reflux overnight. After cooling to room temperature, undissolved solid was filtered. The filtrate was concentrated under reduced pressure to obtain the crude product, which was purified by column chromatography using hexane:dichloromethane $=10: 1$ as the eluent to give pure $N$-butyl-3,6-dibromocarbazole as a white solid (7.61 g, 99\%). ${ }^{1} \mathrm{H}$ NMR (400 MHz, $\left.\mathrm{CDCl}_{3}, 298 \mathrm{~K}\right) \delta$ (ppm): $8.07(\mathrm{~d}, J=2 \mathrm{~Hz}, 2 \mathrm{H}), 7.51(\mathrm{dd}, J=8.7,2 \mathrm{~Hz}, 2 \mathrm{H}), 7.21(\mathrm{~d}, J=9 \mathrm{~Hz}, 2 \mathrm{H}), 4.17(\mathrm{t}, J=7 \mathrm{~Hz}, 2 \mathrm{H})$, $1.82-1.72(\mathrm{~m}, 2 \mathrm{H}), 1.32(\mathrm{dd}, J=15.2,8 \mathrm{~Hz}, 2 \mathrm{H}), 0.91(\mathrm{t}, J=7 \mathrm{~Hz}, 3 \mathrm{H}) .{ }^{13} \mathrm{C} \mathrm{NMR}\left(100 \mathrm{MHz}, \mathrm{CDCl}_{3}\right.$, $298 \mathrm{~K}) \delta(\mathrm{ppm}):$ 139.28, 128.98, 123.40, 123.22, 111.92, 110.38, 43.08, 30.99, 20.50, 13.86.

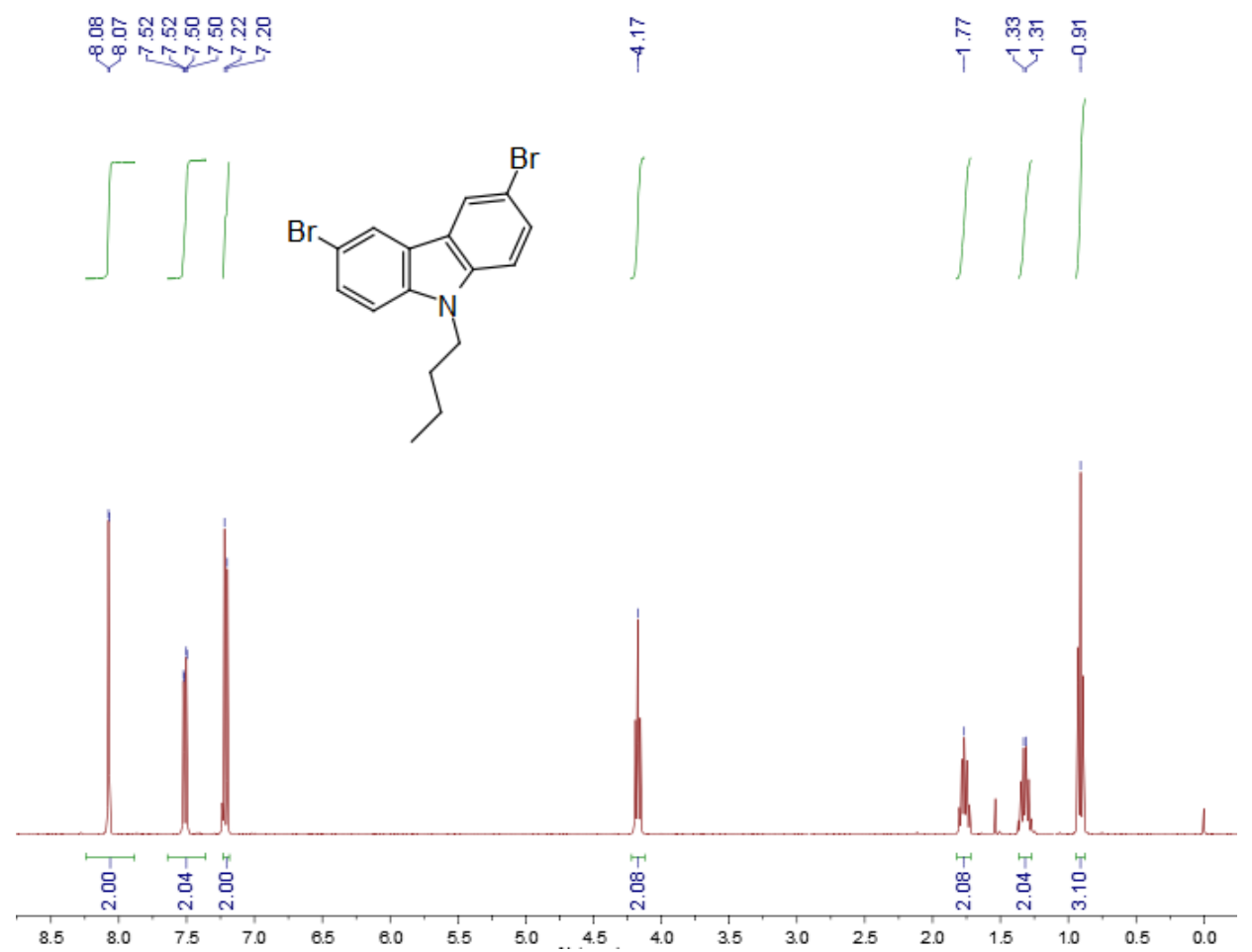

Figure S1. ${ }^{1} \mathrm{H}$ NMR spectrum (400 MHz, $\mathrm{CDCl}_{3}, 298 \mathrm{~K}$ ) of $\mathrm{N}$-butyl-3,6-dibromocarbazole. 


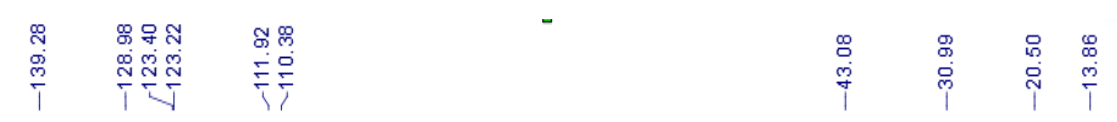

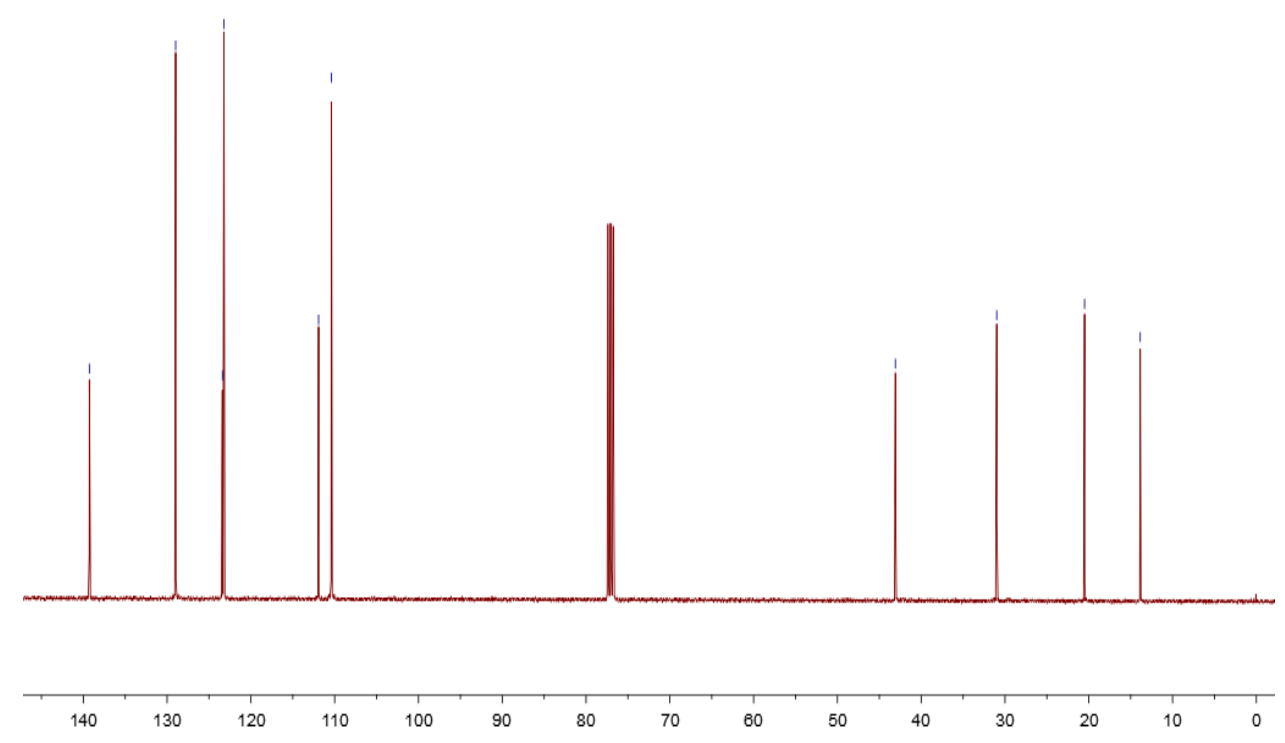

Figure S2. ${ }^{13} \mathrm{C}$ NMR spectrum $\left(100 \mathrm{MHz}, \mathrm{CDCl}_{3}, 298 \mathrm{~K}\right)$ of $\mathrm{N}$-butyl-3,6-dibromocarbazole.

\subsection{Synthesis of cyclo[4] carbazole $(\boldsymbol{C y}[4] \mathrm{C})$}

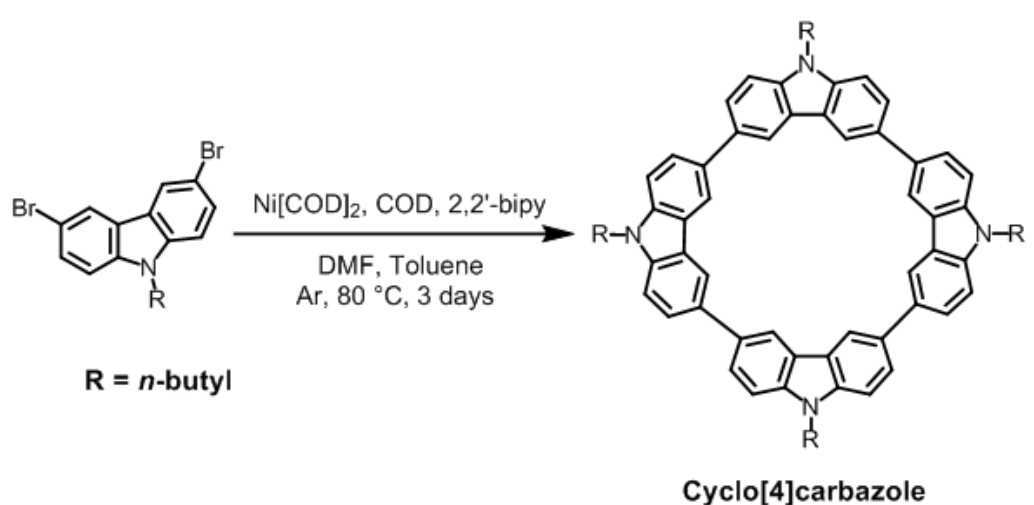

Bis[1,5-cyclooctanediene]nickel(0) (Ni[COD $\left.]_{2}, 1.00 \mathrm{~g}, 3.30 \mathrm{mmol}\right)$, cis-1,5-cyclooctanediene (0.375 g, $3.30 \mathrm{mmol})$ and 2,2'-bipyridine $(0.644 \mathrm{~g}, 4.13 \mathrm{mmol})$ were added into a dry Schlenk tube. Then $5.00 \mathrm{~mL}$ of dry DMF was added to disperse the powder and degassed in liquid nitrogen three times. Under the protection of argon, the suspension was stirred at $80{ }^{\circ} \mathrm{C}$ for $30 \mathrm{~min}$ to form the nickel catalyst complex, which was dark purple. After that, a solution of $N$-butyl-3,6-dibromocarbazole $(0.577 \mathrm{~g}, 1.50 \mathrm{mmol})$ in 10 $\mathrm{mL}$ of toluene was injected dropwise. Three days later, the reaction was quenched with $10.0 \mathrm{~mL}$ of aqueous $\mathrm{HCl}$ and extracted with dichloromethane. The organic layer was concentrated under reduced pressure. To avoid absorption by the silica gel, the crude product was purified quickly by flash column chromatography using DCM:hexane = 1:4 to 1:2 under high pressure to obtain $\mathbf{C y [ 4 ] C}$ as a white solid 
(108 mg, $18.7 \%$ ), mp 186-188 ${ }^{\circ} \mathrm{C} .{ }^{1} \mathrm{H}$ NMR (400 MHz, $\left.\mathrm{CDCl}_{3}, 298 \mathrm{~K}\right) \delta$ (ppm): 8.89 (s, 8H), 7.92 (d, $J$ $=8 \mathrm{~Hz}, 8 \mathrm{H}), 7.52(\mathrm{~d}, J=8 \mathrm{~Hz}, 8 \mathrm{H}), 4.39(\mathrm{~m}, 8 \mathrm{H}), 1.96(\mathrm{~m}, 8 \mathrm{H}), 1.49(\mathrm{~m}, J=8 \mathrm{~Hz}, 8 \mathrm{H}), 1.00(\mathrm{~m}, 12 \mathrm{H})$. ${ }^{13} \mathrm{C} \mathrm{NMR}\left(100 \mathrm{MHz}, \mathrm{CDCl}_{3}, 298 \mathrm{~K}\right) \delta$ (ppm): 140.16, 132.66, 124.49, 124.07, 118.98, 109.04, 43.20, 31.32, 20.67, 13.98. MALDI-TOF: $\mathrm{m} / \mathrm{z}$ calcd for $\left[\mathrm{C}_{64} \mathrm{H}_{60} \mathrm{~N}_{4}+\mathrm{H}\right]^{+}$885.4, found 885.0. HR ESI-MS: $\mathrm{m} / \mathrm{z}$ calcd for $\left[\mathrm{C}_{64} \mathrm{H}_{60} \mathrm{~N}_{4}+\mathrm{H}\right]^{+}$885.4896; found 885.4822; error 8.4 ppm. Furthermore, we obtained the single crystal structure (Figure 1) of $\mathbf{C y}[\mathbf{4}] \mathbf{C}$ and it proved the accurate structure of $\mathbf{C y}[\mathbf{4}] \mathbf{C}$. Owing to the low yields (less than $4 \%$ ), low solubilities and similar polarities of $\mathbf{C y}[n] \mathbf{C}(n=5,6,7)$ macrocycles, it's difficult to separate them. More studies on the separation of $\mathbf{C y}[n] \mathbf{C}(n=5,6,7)$ macrocycles are in progress.

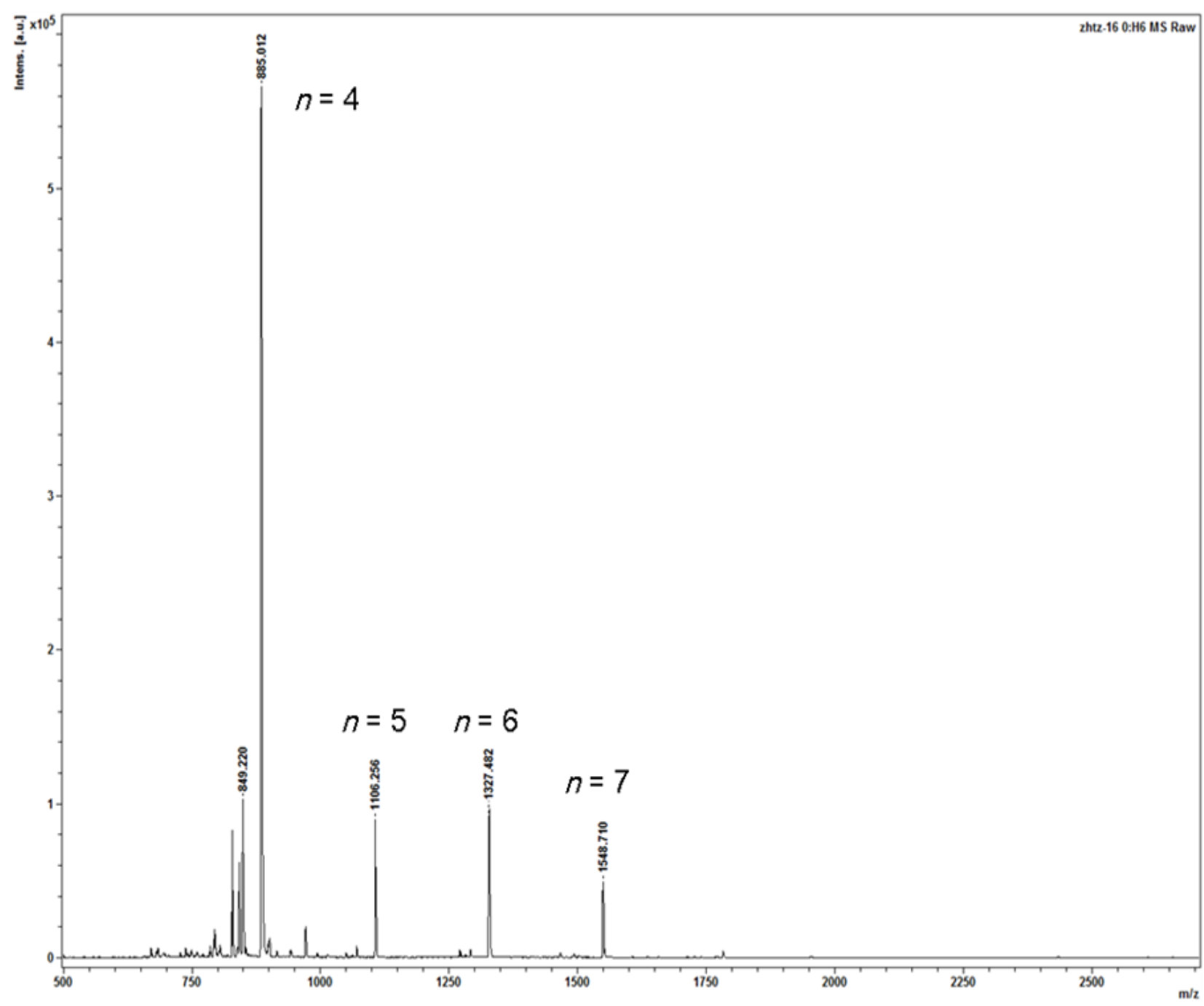

Figure S3. MALDI-TOF mass spectrum of $\mathbf{C y}[n] \mathbf{C}(n=4,5,6,7)$ macrocycles. 


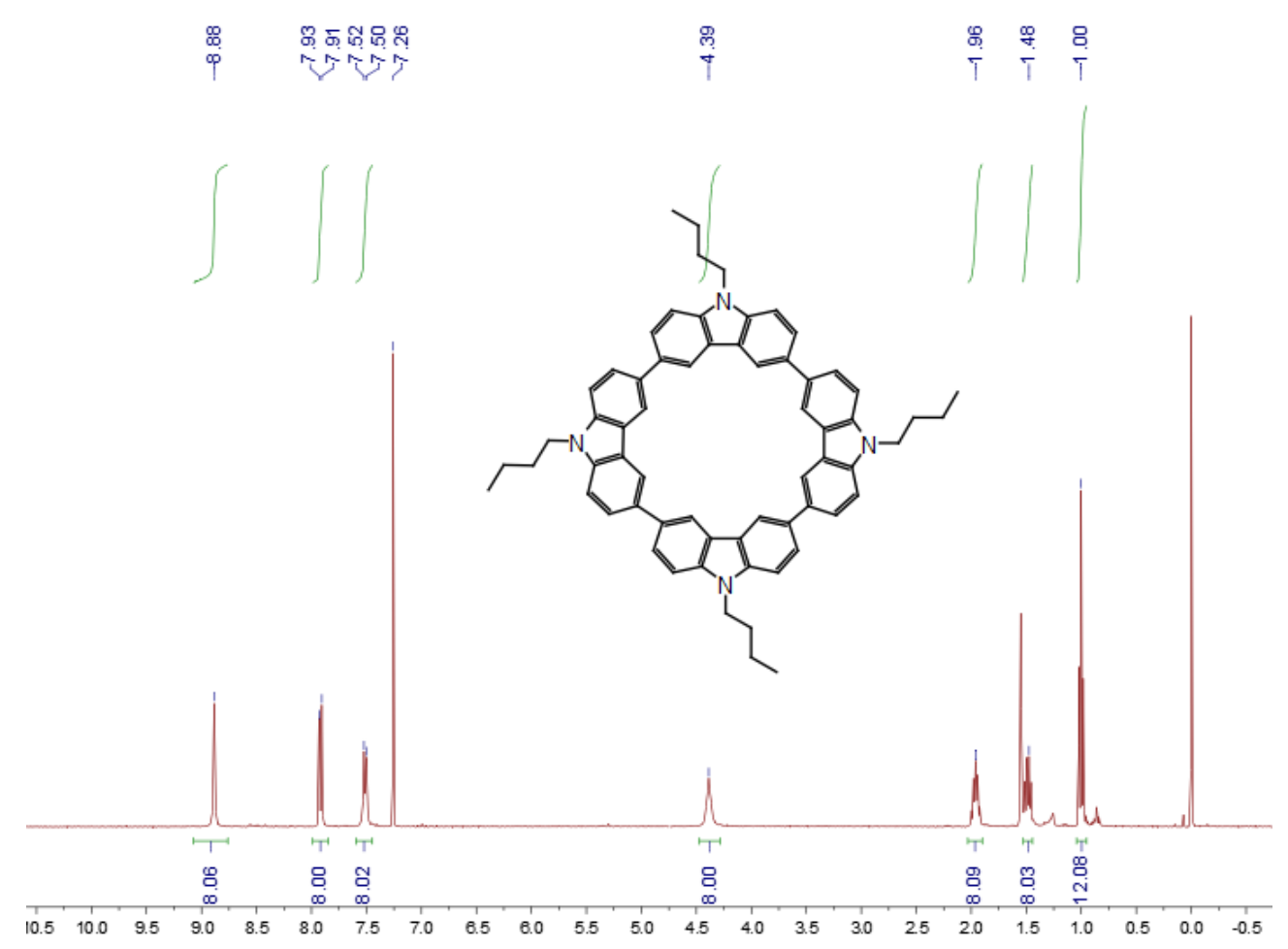

Figure S4. ${ }^{1} \mathrm{H}$ NMR spectrum (400 MHz, $\left.\mathrm{CDCl}_{3}, 298 \mathrm{~K}\right)$ of $\mathbf{C y}[4] \mathbf{C}$.

인

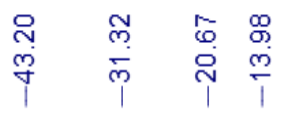

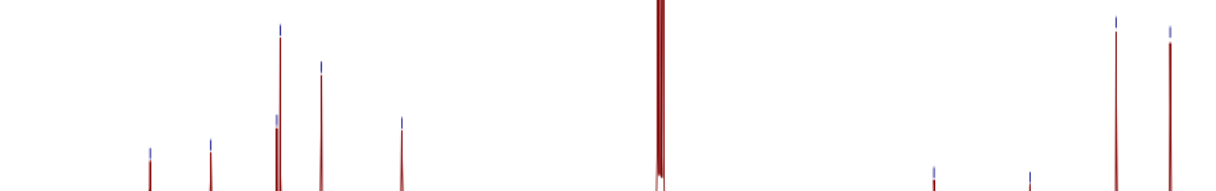

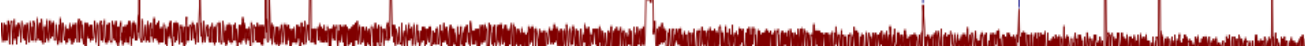

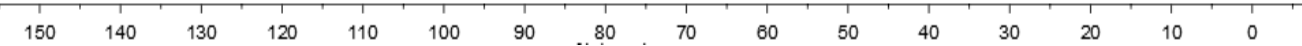

Figure S5. ${ }^{13} \mathrm{C}$ NMR spectrum $\left(100 \mathrm{MHz}, \mathrm{CDCl}_{3}, 298 \mathrm{~K}\right)$ of $\mathbf{C y}[4] \mathbf{C}$. 


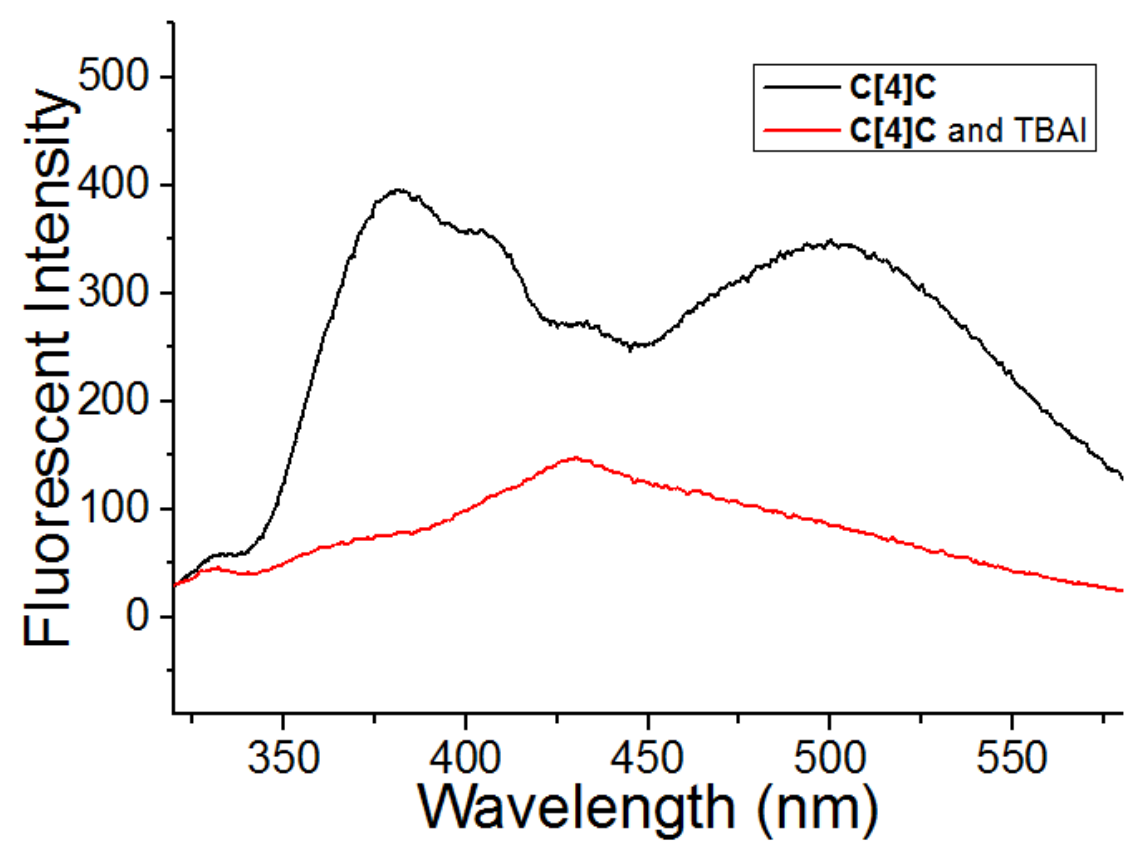

Figure S6. Fluorescence spectra of $\mathbf{C y}[4] \mathbf{C}\left(2.00 \times 10^{-3} \mathrm{mM}\right)$ in $\mathrm{CHCl}_{3}$ in the presence (red) and absence (black) of

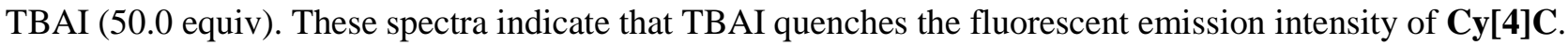

4. Determination of the complexation kinetics for $\mathrm{Cy}[4] \mathrm{C}$ and iodide anion.
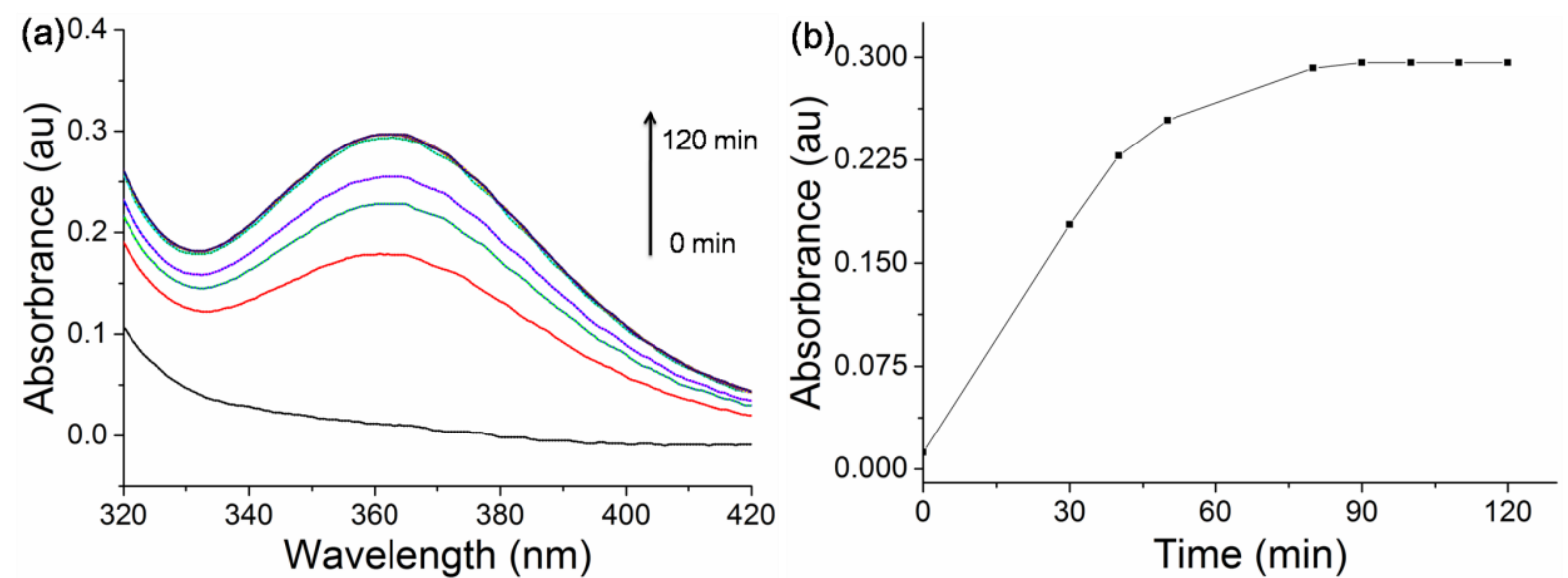

Figure S7. (a) UV-vis absorption intensity changes vs. time after TBAI was added. (b) A plot of the absorption intensity at $360 \mathrm{~nm}$ versus the complexation time. The line was obtained using non-linear curve-fitting. The plot indicates the UV-vis absorption intensity at $360 \mathrm{~nm}$ doesn't change after $120 \mathrm{~min}$. 
5 Partial ${ }^{1} H$ NMR spectra of $\boldsymbol{C y}[4] C$ with various equivalents of TBAI

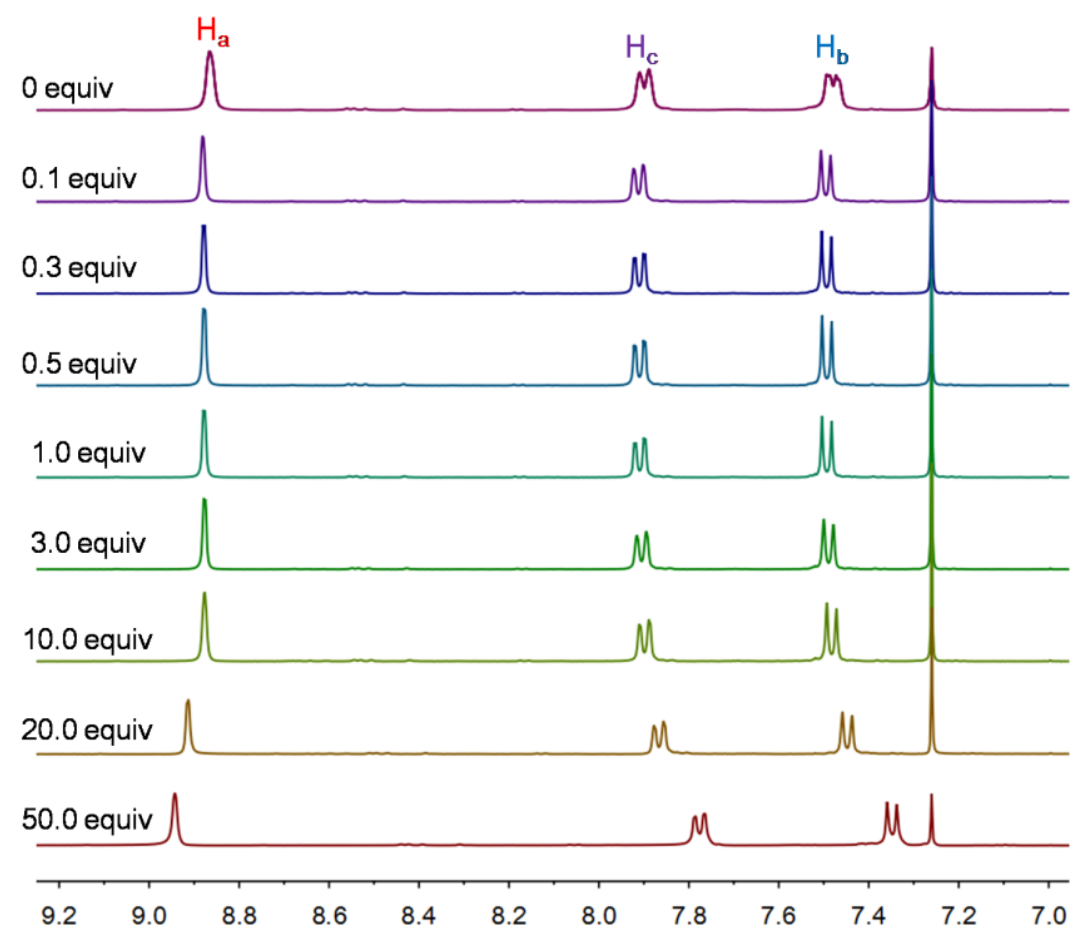

Figure S8. Partial ${ }^{1} \mathrm{H}$ NMR spectra (400 MHz, $\left.\mathrm{CDCl}_{3}, 293 \mathrm{~K}\right)$ of $\mathbf{C y}[4] \mathrm{C}(5.00 \mathrm{mM})$ with various equivalents of TBAI. Each experiment was carried out 2 hours after TBAI was added.

6. High-resolution mass spectrum of a mixture of $\mathbf{C y}[4] C$ and iodide anion

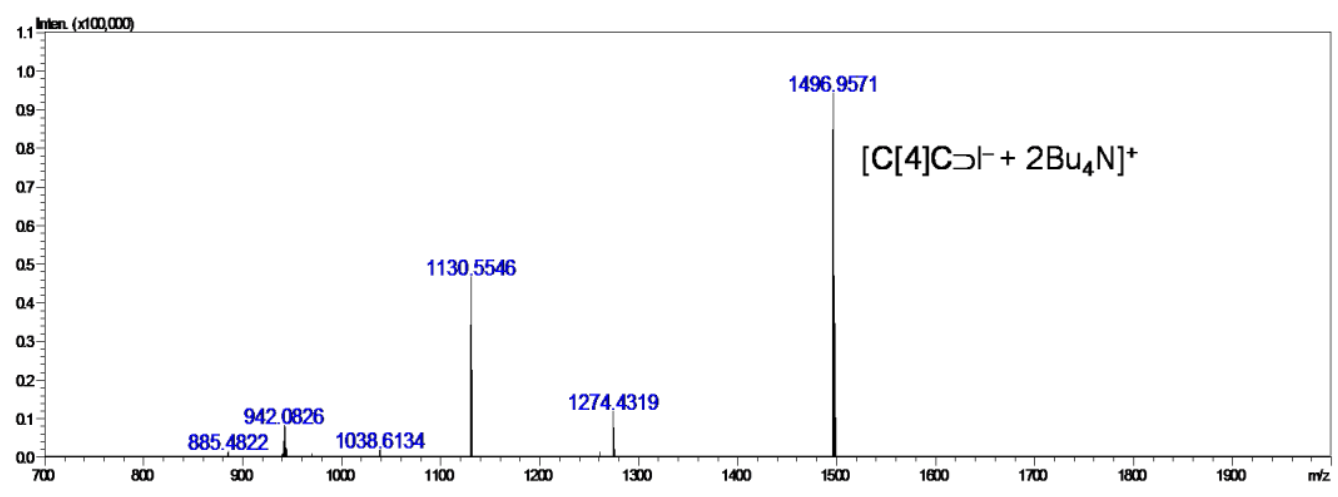

Figure S9. HRMS spectrum of a mixture of $\mathbf{C y}[4] \mathbf{C}$ and TBAI. A peak was found for the 1:1 complex of $\mathbf{C y}[4] \mathbf{C}$ and iodide anion: $m / z$ : calcd for $\left[\mathbf{C y}[4] \mathbf{C}_{\mathrm{I}^{-}}+2 \mathrm{Bu}_{4} \mathrm{~N}\right]^{+}\left[\mathrm{C}_{96} \mathrm{H}_{132} \mathrm{~N}_{6}\right]^{+}$1496.9586, found 1496.9571, error -1.0 ppm. 
(a)

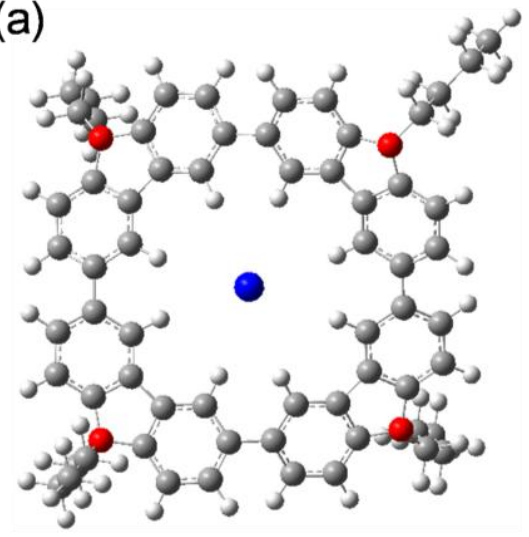

(b)

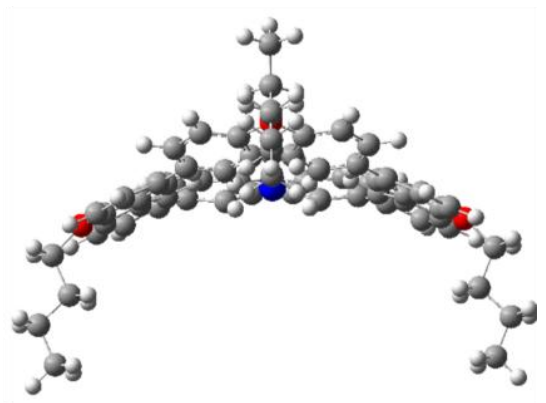

Figure S10. PM6 molecular model of the $\mathbf{C y}[4] \mathrm{C} /$ iodide anion complex: (a) top view; (b) side view. Carbons are gray, hydrogens are white, nitrogens are red, and iodide anion is blue.

\section{Determination of association constant $\left(K_{a}\right)$ of $\boldsymbol{C y}[4] C$ and iodide anion ${ }^{S 2}$}

The association constant $\left(K_{\mathrm{a}}\right)$ of $\mathbf{C y}[\mathbf{4}] \mathbf{C}$ and iodide anion was determined by UV-vis absorption titration. Different volumes of a chloroform solution with high concentration of TBAI (4.00 mM) and low concentration of $\mathbf{C y}[4] \mathbf{C}\left(4.00 \times 10^{-4} \mathrm{mM}\right)$ were added to a chloroform solution with the same low concentration of $\mathbf{C y}[4] \mathbf{C}$ to result in absorption ascending at $360 \mathrm{~nm}$. Absorption changes towards different concentrations of TBAI were treated with non-linear curve-fitting to afford the $K_{\mathrm{a}}$ value of 81.76 ( \pm 9.22$) \mathrm{M}^{-1}$. Non-linear curve-fitting was using the equation: $A=\left(A_{\infty} /[\mathrm{H}]_{0}\right)\left(0.5[\mathrm{G}]_{0}+0.5\left([\mathrm{H}]_{0}+1 / K_{\mathrm{a}}\right)-\left(0.5\left([\mathrm{G}]_{0}^{2}+\left(2[\mathrm{G}]_{0}\left(1 / K_{a}-[\mathrm{H}]_{0}\right)\right)+\left(1 / K_{a}+[\mathrm{H}]_{0}\right)^{2}\right)^{0.5}\right)\right.$ (Eq. S1)

Where $A$ is the absorption intensity at $360 \mathrm{~nm}, A_{\infty}$ is the absorption intensity at $360 \mathrm{~nm}$ when the host is completely complexed, $[\mathrm{H}]_{0}$ is the fixed initial concentration of the host, and $[\mathrm{G}]_{0}$ is the initial concentration of the guest. 

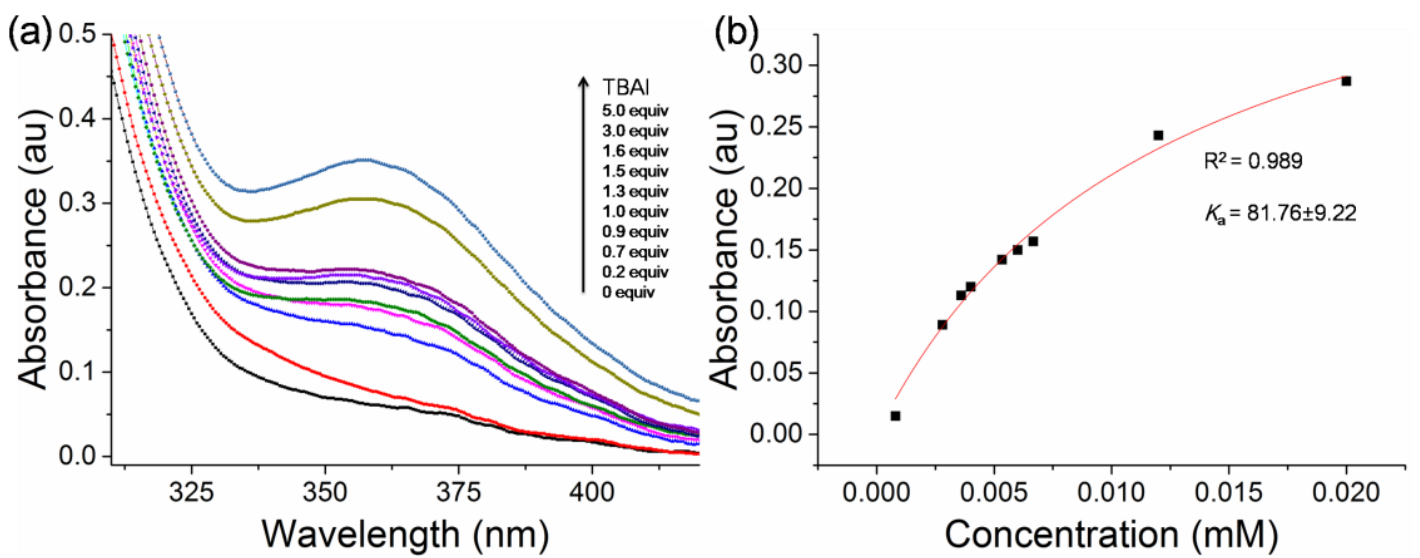

Figure S11. (a) Absorption spectra of $\mathbf{C y}[4] \mathrm{C}$ in $\mathrm{CHCl}_{3}$ with increase in the concentration of TBAI; (b) A plot of the absorption intensity at $360 \mathrm{~nm}$ versus the TBAI concentration. The red line was obtained from non-linear curve-fitting using Eq. S1.

\section{X-ray crystal data for $\mathrm{Cy}[4] \mathrm{C}$}

Crystallographic data: block, green, $0.48 \times 0.46 \times 0.43 \mathrm{~mm}^{3}, \mathrm{C}_{64} \mathrm{H}_{60} \mathrm{~N}_{4}, F W 885.16$, trigonal, space group $R-3, a=31.6291(13), b=31.6291(13), c=12.7824(5) \AA, \alpha=90.00^{\circ}, \beta=90.00^{\circ}, \gamma=120.00^{\circ}, V=$ 11074.4(8) $\AA^{3}, Z=9, D_{\mathrm{c}}=1.195 \mathrm{~g} \mathrm{~cm}^{-3}, T=170.3 \mathrm{~K}, \mu=0.069 \mathrm{~mm}^{-1}, 23613$ measured reflections, 4483 independent reflections, 320 parameters, 6 restraints, $F(000)=4248, R(\mathrm{int})=0.0348, R_{1}=0.1051, w R_{1}=$ 0.2639 (all data), $R_{2}=0.0837, w R_{2}=0.2344[I>2 \sigma(I)]$, max. residual density $1.086 \mathrm{e} \bullet \AA^{-3}$, and goodness-of-fit $\left(F^{2}\right)=1.026$. CCDC 1476369 .

\section{X-ray crystal data for the complex of $\mathrm{Cy}[4] \mathrm{C}$ and chloroform}

Crystallographic data: block, green, $0.48 \times 0.40 \times 0.30 \mathrm{~mm}^{3}, \mathrm{C}_{66} \mathrm{H}_{62} \mathrm{~N}_{4} \mathrm{Cl}_{6}, F W 1123.90$, monoclinic, space group $P 2{ }_{1} / c, a=16.487(2), b=19.2778(17), c=18.1092(18) \AA, \alpha=90.00^{\circ}, \beta=101.874(11)^{\circ}, \gamma=$ $90.00^{\circ}, V=5632.7(10) \AA^{3}, Z=4, D_{c}=1.325 \mathrm{~g} \mathrm{~cm}^{-3}, T=171(4) \mathrm{K}, \mu=0.351 \mathrm{~mm}^{-1}, 16205$ measured reflections, 16193 independent reflections, 690 parameters, 0 restraints, $F(000)=2352, R(\mathrm{int})=0.0000$, $R_{1}=0.1701, w R_{1}=0.3038$ (all data), $R_{2}=0.1013, w R_{2}=0.2657[I>2 \sigma(I)]$, max. residual density 1.258 $\mathrm{e} \bullet \AA^{-3}$, and goodness-of-fit $\left(F^{2}\right)=0.961$. CCDC 1477258 . 
11. References

S1. (a) Ku, C.-H.; Kuo, C.-H.; Chen, C.-Y.; Leung, M.-K.; Hsieh, K.-H. J. Mater. Chem. 2008, 18, 1296-1301. (b) Gudeika, D.; Grazulevicius, J. V.; Volyniuk, D.; Butkute, R.; Juska, G.; Miasojedovas, A.; Gruodis, A.; Jursenas, S. Dyes and Pigments. 2015, 114, 239-252.

S2. (a) Connors, K. A. Binding Constants; Wiley: New York, 1987. (b) Corbin, P. S. Ph.D. Dissertation, University of Illinois at Urbana-Champaign, Urbana, IL, 1999. (c) Ashton, P. R.; Ballardini, R.; Balzani, V.; Belohradsky, M.; Gandolfi, M. T.; Philp, D.; Prodi, L.; Raymo, F. M.; Reddington, M. V.; Spencer, N.; Stoddart, J. F.; Venturi, M.; Williams, D. J. J. Am. Chem. Soc. 1996, 118, 4931-4951. 